\title{
A Legal Approach to Prevent Road Accident in Bangladesh: Drawbacks and Recommendations
}

\author{
Md. Aktarul Alam Chowdhury \\ Assistant Professor, Department of Law, International Islamic University Chittagong \\ Md. Hasnath Kabir Fahim \\ Advocate, Chittagong District Bar Association (CDBA), Chittagong Bangladesh
}

\begin{abstract}
As a serious man-made epidemic and distressing occurrence in the community is known road accident, which is affected though personally but afterwards harsh impact goes to social and economies field Major concern is road traffic accidents and picture of injuries have now emerged as outrageously or tremendously. The alarming rate of dreadful road traffic accidents may have increased due to certain reasons: lack of political concern, lack of accountability of the principal category of law abiding citizens, incompetent drivers, inadequate punishment etc. In a country with limited resources, like Bangladesh it considered as hinders of all development and caused worst impact on GDP. This study focused on observing the behavior of law abiding pedestrians and drivers; and try to relation under the obligation of Law as the sole identity of citizenship. Also, the road safety situation how developed and some contemporary issues and priorities are briefly discus in this dissertation.
\end{abstract}

Keywords: Safety, Transport, Traffic, Accident, Injure, Problem, Punishment.

DOI: $10.7176 / \mathrm{JLPG} / 81-07$

\section{Introduction}

Urbanization is treated to be a global phenomenon and it is taking place at a speedy rate in many of the least developed and developing countries of the world. Like many other developing countries, rapid urbanization in Bangladesh caused unbearable traffic problems and immediate demands of infrastructure and methods to minimize sufferings in the urban area of the country. Being a densely populated country Bangladesh has been enduring uncountable road accidents due to severe traffic hazards which have taken an epidemic form. In the cities of Bangladesh, road accident is increasing day by day and common people become the ultimate victim in their day to day life (K.D.A, 2008). Some of the common occurrences of the vital cities of Bangladesh are road accidents and traffic congestion. Among the remarkable unban cities of Bangladesh like Dhaka, Chattogram, Rajshahi and Khulna mainly the Dhaka and Chattogram are now suffering serious traffic problem along with other inconveniences like insufficient drainage, unplanned housing, water, gas and electricity load shedding (Osman, 2010). Such accident in road all over Bangladesh is harming the economic and environmental development of the country and such agony seems to be beyond control. Damage in both economic and environmental issues is quite threatening for a developing country like Bangladesh.

Bangladesh is treated to be one of the least motorized countries of the world and in the high ways of the country, the condition of accident casualty is worst and many of the culprits vehicles are heavy vehicles like buses and trucks (Sharmeen 2011). Many of the trucks are locally modified after import and reckless drivers with overloaded trucks are often seen. Unfortunately for the development of transport facilities very limited resources are invested in Bangladesh. Ongoing growth of population with limited space available for new roads, coupled with the rapid rise in transport demand, existence of a huge number of non-motorized vehicles on roads, lack of application of adequate and sufficient traffic management system have added more sufferings in almost every urban areas of Bangladesh. It is sorrowful to state that almost 40 percent of the drivers in the country drive 9 to 12 hours a day at a stretch and about 95 percent of the drivers have to drive for more than 12 hours under coercion (Sufian 2013). Many drivers directly complain that they do not get proper time to take rest and sleep which is a material fact of road accidents. Almost majority of the drivers of buses and trucks do not receive any institutional training but get their training privately while worked as a helper or conductor (Sharmeen 2011). Many of these drivers pay extra fees and get the licenses by managing some corrupt personnel of the license authority.

According to the report of Bangladesh Road Transport Authority (BRTA) in 2016, around 2,166 people die every year due to road accidents. Another private report of NISBA says that 2.316 road crashes took place in 2016 where almost 4,144 people lost their lives along with 5,225 people got injured. Remarkably in 2015, 2,626 road accidents held killing near about 5,300 people. The number of injured was 6,197. The rate of such death and injury was almost same in the year of 2014. In 2014, 2,713 road accidents killed about 6,582 people and injured 10,770 people. In the statistics of NISBA it was revealed that almost 2000 road accidents take place every year in Bangladesh which caused death of more than 5,000 people. Centre for Injury Prevention and Research (CIPRB) says that everyday 64 people die in Bangladesh due to road accidents. In 2016 a survey was made by 
Bangladesh Health Injury Survey (BHIS) where it was found that road accidents kill around 23,166 people every day. After a long research over last 10 years by Analysis BD it is seen that approximately 63,000 people died in road accidents. According to this statistics in 2018 near about 3,132 people died due to road crashes. Professor Moyazzem Hossain, director of Accident Research Institute at BUET said the country suffers a loss of 34,000 million taka every year in road crashes. Bangladesh suffers a big economic loss because of road accidents.

As the accidents due to traffic is increasing at an alarming rate, taking proper measure is the demand of time now to mitigate such traffic hazards in Bangladesh. Dhaka, the capital and Chattogram, the commercial capital of Bangladesh have remarkably faced various road accidents in very cumbersome way (Shamsher 2013). Extra attention shall be paid depending upon the nature and fatality of road accidents in Bangladesh (Sharmeen 2011). Issues regarding different road users, road, roadside factors and environment should also be considered as these involve very complex matters.

Objectives

This paper investigates some reasons and issues of road accidents across Bangladesh. Taking the present perspective into consideration, this paper has been directed on the foundation of the following specific objectives:

1. To study the causes of accidents and identify the measures to minimize road accidents;

2. To overview the existing legal frameworks and their methods of factual enforcement;

3. To suggest few remedial methods for collective awareness among both pedestrians and drivers. Methodology

In order to trace the identified research objectives of the study, both the quantitative and qualitative research methods were used. Primary and secondary data and information were thus collected and discussed that enables this paper to explore the behavioral reasons behind the traffic accidents in roads of Bangladesh.

\section{Road Safety as a Burning Issue}

One of the prominent causes of death around the world is road traffic accidents and in some cases it has become the number one reason cause. Every year approximately 50 million people get injured and 1.3 million people die due to road accidents. Thousands of people die every year as a result of road accidents. Most often, low and middle income people face injuries and fatalities of road accidents. A heavy burden on health services and economies is placed by road traffic injuries. It is estimated that the economic cost of road crashes and injuries is 1 percent of gross national product (GNP) in least developed countries, 1.5 percent in developing countries and 2 percent in developed countries (Sufian 2013).

Bangladesh is a developing country along with very accident prone one. As per the statistics of police department of, road accidents, on average take 4000 lives and injure another 5000 a year in Bangladesh. Road accident casualty rate in very high in Bangladesh and the figure indicates that more than 60 deaths per 10,000 motor vehicles (Sharmeen 2011). Around eight persons die in road accidents every day. Among various types of road accidents, pedestrian accidents are the prominent one in Bangladesh. Accidents by truck have taken the second position but all the accident examples seem to follow decreasing trend. According to survey of Bangladesh Road Transport Authority (BRTA) from 2016 to 2018 there has been tremendous increase of motorcycles in Bangladesh and almost 4,144 death crashes took place in 2016, 5,645 in 2017 and 3,414 in 2018. National Committee to Protect Shipping, Roads and Railways prepared the report stating that almost 6,000 people were wounded in 2,353 road accidents during January-June of 2017.

\section{Overview of Etiological Factors}

Many factors are there responsible for these grievous road crashes. But the observed material deficiencies of local transportation mechanism can be elaborately discussed in two streams: both functional and geometric errors. Causes like unplanned mixture of vehicle stream with non-lane based theory, residue problematic vehicle number and behavior to drive recklessly are some of the remarkable examples of functional deficiencies. Apart from these, geometric defects are defective designed road pattern, exceeding damage in rainy season, lack of proper management of road network etc are notable responsible issues. Sudden local roadway accidents and roadside crashes are provoked by these deficiencies.

The most unwanted thing to happen to a road user is the road accidents. Though these crashes occur often but people forget to take lesson from it. Human errors are the main causes of road accidents in Bangladesh. Both the drivers and pedestrians are equally liable for road accidents and crashes. Some of the common behavior of human which causes road accidents are like over speeding, drunken driving, distractions to drivers, red light jumping, avoiding safety gears such as seat belts, non adherence to lane driving, overtaking in a wrong manner and etc (Sharmeen 2011). According to the WHO Global Status Report of 2013 on Road Safety indicates five factors of road accidents such as excessive speed, drunk driving, non use of motorcycle helmets, non use of seat belts and non use of child constraints. 


\subsection{Safety Issues of Pedestrian in Bangladesh}

Pedestrian such as a baby to an old aged person, everyone is a pedestrian. As the pedestrians don not have any extra measures for their protection, so they become more injured of road accidents in comparison to other road user groups. It is a matter of sorrow that these people get less attention than vehicular traffic. Bangladesh is a densely populated country and the most important mode of transportation for the people is walking. Such walking is involved in over 60 percent of all urban trips and 65 percent of them are trip of short distance. According to the modal shares in Metro of Dhaka from Japan Bank for International Cooperation (JBIC) 1999 it is concluded that walking is of the highest percentage among all types of trips. Safety problem of pedestrian is now an issue of great concern as because everyday road accidents injure or kill a notable number of pedestrians around the country. According to the report of Police Department during 2000-2009, more than 45 percent of complained road accidents and 52 percent of grievous crashed are within the pedestrians of Bangladesh. In urban areas, around $80 \%$ of the pedestrian accidents occur and rest in rural areas. In national highways the highest pedestrian injuries are occurred and second highest in the roads of city areas. It is pertinent to note that most vulnerable pedestrian group is 6 to 10 years and within 26 to 30 years fall another risky group (Sufian 2013). On the edge of the road, prominent number of pedestrian accidents is occurred. Some of the extreme issues are observed while crossing the roads. This incident occurs as there is no foot over bridge in many urban areas around Bangladesh. From such situation it is local pedestrians are not very much aware of and willing to follow the traffic rules when crossing roads and this is how the rate of death due to road accidents are increasing gradually. It is found that among the victim pedestrians 81 percent are male and 19 percent are female and most often such road crashes occur in day time. The major contributors of road accidents are heavy vehicles. In Bangladesh it is observed that both the pedestrians and drivers are equally responsible for road accidents. The condition is getting more deteriorated due to inadequate, insufficient and less education in law enforcement.

\subsection{Safety Problem regarding Non-Motorized Vehicles}

The role of non-motorized vehicles becomes inevitable when discussing safety issues and features of vehicles because it has become an easier mode of transportation in entire world both in the form of rickshaws or bicycles. According to the statistics of Japan International Cooperation Agency (JICA) almost 39 percent of all personal trips are carried out by rickshaws in Bangladesh. Along with these about 35 percent of the total vehicles are nonmotorized in Bangladesh. So there is an inherent relation between road accidents and non-motorized vehicles. According to the reports, 45,891 road accidents occurred in Bangladesh from 1998 to 2010 and among these 4,865 are relating non-motorized vehicles (Sufian 2013). Three elements which are incorporated with road accidents are road, road users and road environment. Road users include both human and vehicles. All these three elements play vital role in incidents of road accidents. To ensure overall road safety, involvement of vehicle factors in road traffic accidents is very crucial.

Vehicle maneuver should be considered as an important parameter while discouraging vehicle factors of non-motorized vehicle accidents. According to the analysis of accident database a total of 4,710 non-motorized vehicle accidents occurred in different vehicle maneuvers during 1998 to 2015. Among these when the nonmotorized vehicle was moving forward, 87 percent non-motorized vehicle accidents occurred as well as 3 percent occurred when the vehicle was in parking. Unfortunately when the non-motorized vehicles were moving in reverse direction and turning left, most of the fatal non-motorized vehicles accidents occurred and the criteria of fatality were very severe (Sufian 2013). For the above two cases of vehicle maneuvers, 81 percent and 78 percent accidents were fatal respectively.

One of the most primary reasons of road traffic accidents is considered as vehicle defects. According to the studies carried out in developing countries, 2 to 8.5 percent of accidents are directly caused by defective vehicles. Defective vehicles in developing countries are most often a pronounced factor in road accidents as the maintenance and condition of vehicles usually much worse. Data regarding accidents from 1998 to 2010 discloses that due to defects of non-motorized vehicles a minor portion of road accidents occurred. It is also found that in 91 percent accidents of road, non-motorized vehicles had no defects actually. Due other traffic, road and other issues they got involved in accidents and crashes. Defects in brake system, error in steering system, problem with lighting system are some of the common defects of vehicles. As per survey report of Individual Accident Report Forms (ARF), it is demonstrated that 16 percent cases of accidents of rickshaw and bicycle somehow involved motorized vehicle had fault in brakes. About 94 percent of trucks involved in road accidents were in suitable condition of loading which is observed by MAAP database. In 2009, it was seen that 9 percent of trucks involved in accident which had bad loading. Very often bad loaded trucks are seen in both rural and urban areas of Bangladesh which get commonly involved in horrible road accidents. There is necessity of extra space for the movement when more extension of load is created and often there may be an unauthorized side extension. Such kind of dangerous rear extension of loading is very dangerous though with the help of ropes or other means 2.5 feet rear load is kept suspended and this may easily hamper safety issues (Sufian 2013). 


\subsection{Accidents of Heavy Vehicles in Bangladesh}

In Bangladesh trucks, heavy trucks, buses and minibuses are major heavy vehicles and it is not only in terms of registration but also from the concern of safety hazards. It has become a common practice for the heavy vehicle drivers to violate the traffic laws and drive according to their sweet will. To add to this problem, owners and manufacturers of the vehicles do pay much attention to the standard in the issue of loading, maintenance and body modification. Trucks and buses are made killer giants on roads by these issues in Bangladesh.

More than 60,000 accidents took place by bus and minibus in last 15 years which have contributed 33 percent of overall road accidents in Bangladesh (Sufian 2013). In national highways bus accidents are mainly takes place and in city roads minibuses are found to get involved in traffic accidents. Analysis shows that trucks and heavy trucks are involved in 22 percent of accidents. In case of all other accidents, severe fatality is caused in 65 percent while it is 70 percent in case of truck accidents. So, extra attention is very essential in the perspective of Bangladesh. Truck accidents along with their increasing severity, over speeding, careless driving and unconscious pedestrians are the main factor of road accidents by trucks and heavy trucks. Due to over speed rate of truck accidents is very high in Bangladesh. When passenger is responsible for accident then rate of fatal truck accident is very high as well as for careless driving total number of truck accident is also very high (Sharmeen 2011). At every incident of truck accidents, most of the vehicles involved some kind of defects. It is matter of sorrow that this rate is increasing day by day. In the cases of truck accidents, 15 percent trucks had brake problem, 4 percent had defects in lighting system, 3 percent with defective tires, 1 percent trucks had errors in steering and 8 percent contained many other mechanical defects (Sufian 2013). It is quite unfortunate that many of such cases remain untraced.

Depending upon the maneuver types of truck vehicle both the number and severity of truck accident actually vary in many situations. Overtaking, during taking of turn, proceeding ahead and sometimes going backward without due concern and proper signal have added the reasons of truck accidents in the list of road accidents. Many of the trucks get involved in road accidents even after having good loading condition. Similarly the situation gets to worse when the trucks are with bad loading condition. In Bangladesh the bad loaded trucks are often seen and the law enforcing agency is not much aware of such violation of rules as they receive financial interest from both the drivers and owners (Siddiqui 2016). The shape of the loads is often hazardous and weights are also excessive.

\subsection{Vehicles with Reduced Life Anticipation}

There is serious lacking in local road safety domain to differentiate causality and association that is reason and understand the vital factors which are connected to traffic accidents situation. It is recently seen that unsafe and congested road network in local area is indulging the fast aging of casual service life of vehicle. In Bangladesh research on driver's behavior shows that more than 30 percent of the entire respondents agreed that they often have in mind and start competition on road and almost 80 percent of them tries to get the attitude of leaders of road. Such deeds of the drivers regularly provoke head-on and rear-end collisions (Siddiqui 2016). A determinant factor in accelerated vehicle aging is played by such competitive aggressive attitude. In the cities of Dhaka and Chattogram such competitions of drivers are regularly suffered by the passengers (Shamsher 2013). These drivers often do not pay attention to the request of the passengers to drive slowly. In most of the urban areas repeated applying of brakes, clutches, accelerators are highly necessary and constitutes harassing vehicle hit and side swiping form friction. Thus number of insecure and road unfriendly vehicles are increasing gradually. Among the poor roadway safety, vehicle damage and increase in vehicular collision such continuous vicious loop is encircling. In many experiments it is opined that service life of buses in intra city is quite double than that of inter city and it indicates the rapid collapse of service life in urban vehicles. There is no doubt that vehicle with quality materials and parts have more life time service. Relevantly in Bangladesh buses or truck with low quality have less service life and shortly become unfit (Sufian 2013). After second hand purchase the decreased lifespan of vehicles is another imperative outcome. It is to be mentioned that the service life of a second hand purchased bus or truck is almost one-fourth of that of quality vehicles because many vital parts of that second hand vehicle are not in the similar condition when it was new. During the first hand driving many rough pattern driving might be taken which causes severe inner damage to the vehicles. With only simple thick layer of exterior painting defective and aged vehicles ply on roads. Such vehicles are taking the full advantage of weak monitoring system and have become threatening for overall road safety across the country.

\section{Legal Frameworks and Institutions}

Motor Vehicle Ordinance, 1983 is the most vital governmental legal authority under legal instrument guiding all issues relating to road, traffic and road safety. The Bengal Motor Vehicle Rules, 1940 and Motor Vehicle Rules, 1984 are the other relevant and administrative instruments. Along with these legislations there are Dhaka Metropolitan Police Ordinance, Chittagong Metropolitan Police Ordinance, Khulna Metropolitan Police 
Ordinance, Rajshahi Metropolitan Police Ordinance, Barisal Metropolitan Police Ordinance, Sylhet Metropolitan Police Ordinance, Police Act and High Way Police Rules to handle the issues of road and traffic management. Bangladesh Road Transport Authority (BRTA), Metropolitan Police, Highway Police and District Police are the material bodies vested with the authority of enforcement of all relevant laws in Bangladesh. Three major regulatory institutions and two engineering departments are there with duties and responsibilities regarding road safety and other relevant issues.

BRTA is the regulatory body responsible for vehicle management and driver licensing, the Road Transport Committee (RTC) under BRTA is responsible for route franchising and police department. Roads and Highway Department (RHD) and Local Government Engineering Department (LGED) are the two engineering bodies with responsibilities for the highways and feeder roads respectively. Along with these the Accident Research Institute (ARI) at Bangladesh University of Engineering and Technology (BUET) is there to maintain an accident data base. The National Road Safety Council (NRSC) was established in 1995 with an aim to provide a strategic vision on the concept of road safety.

\subsection{Road Transport Act, 2018 at a Glance}

The government of Bangladesh has given approval to the draft of a new law for roads named as the Road Transport Act, 2018 containing provisions of a maximum penalty of five years of confinement in prison and a half million taka as fine for causing death in road accidents. The offenders can also be tried under the Penal Code, 1860 carrying death sentences as the maximum penalty in case of a road accident is found to be intentional.

The new law has framed the maximum age and educational qualification for achieving driving license. A person must pass class 8 to be a driver and to be driver's assistant he must pass class 5 . In both the cases one must be 18 years of age for getting a driving license. A 12 point system for driving license has been launched by the new legislation and has also fixed the number of vehicles a family or organization can use. Provisions relating working hours, compensation fund and emergency helpline are well introduced in this new law. Under the traffic laws of country action can also be taken against government officials for faults on roads. The newly promulgated law described punishment for using mobile phone during driving, driving under influence of narcotic substances, driving on wrong lane, occupying reserved seats, riding on motor bikes without helmets and many more.

Apart from the advantages of the new Road Transport Act, 2018 there are some disadvantages. The act does not mention any proper mechanism of protection against loss or damage and process of insurance of the risk. Check and balance system for law enforcing authority has not been ensured in the act and as a result innocent people will be victimized. The act does not emphasis fairness in respect of BRTA while providing license which is one of the vital causes of road accidents.

\section{Factors behind Road Accidents}

\subsection{Excessive and Inappropriate Speeding}

A serious safety hazard is imposed by speed differentials and excessive speeds in the built up sections of the highways. Non existence of service roads and system to reduce speed contribute much on causing of road accidents (Siddiqui 2016). A profound effect on road accidents is created by vehicle speed. Aggressive speed is of the reasons of road accidents in Bangladesh. Due to such aggressive speed drivers often fail to control speed in curves of the road. Breaking at the necessary point becomes difficult while driving at an aggressive speed. Aggressive speed in also seen both in highways and subways. Most of the drivers often forget that they are liable to drive safely and saving time is not the real fact (Sharmeen 2011).

\subsection{Breach of Rules is a trend}

Road communication of Bangladesh is now filled with the violation of laws and anarchy. Driver often willfully violates the rules and regulations of the road causing uncountable accidents. This is the same scenario overall the country and these violent drivers do not pay hid to abide by laws. Drivers of buses, vans, trucks, micro-bus and private cars are regularly get engaged in wild races without the nominal respect for human rights. As per the statistics around 20,000 road accidents took lives of almost 4,000 people around the country (Sharmeen 2011). In addition, a quarter of million people suffered from grievous injuries in many road crashes.

\subsection{Lack of Maintenance of Roadway}

Having no proper maintenance on the transport system has indulged the occurrence of road accidents in Bangladesh. Major roads network like 20,000 kilometer has become potholed due to absence of proper maintenance. Dilapidated road systems, improper management intersections, violation of traffic laws and irregular increase of vehicles have the highways of Bangladesh horrible (Uddin 2003). Due to absence of repair and timely management, numerous potholes are developed in highways and intra-district roads. 


\subsection{Incompetent Driver}

No formal training is there for public transport drivers in Bangladesh and they actually work for overtime (Sharmeen 2011). Often license is provided to unqualified drivers by adopting unfair means. Frequent accidents take place due to reckless overtaking on highways. Essentials to reduce speed rate must be built at risky bends of the roads. Driving recklessly, blind curves and no less measure to reduce speed at road have led to many fatal and heinous road accidents (Siddiqui 2016). Fearless overtaking has worsened the situation in many vital areas of the country. In many highways of the country there is no mechanism to reduce the speed level of the vehicle and often vehicles don not follow the lines of the road and commit collisions with other vehicles and humans. Many helpers of the buses and trucks are seen to take over wheels with forged license having no adequate training.

\subsection{Heavy Vehicles in Road Accidents}

The issue of uncontrolled involvement of heavy vehicles like trucks and buses in road accidents and fatal injuries are common phenomenon in Bangladesh (Siddiqui 2016). In most of the Asian countries these heavy vehicles are the main contributors of road accidents (Sharmeen 2011). Over involvement of heavy vehicles in Bangladesh has taken the rate of road accidents very high. These vehicles are not only dangerous for other vehicles but also for pedestrians as well.

\subsection{Curve and Risky Spot of the Road}

Curved roads are often component of road accidents as unskilled drivers with aggressive speed make most of their collisions in curves of the roads. Many curved roads of the highways sometimes do not show the sign to help the drivers to get idea about the pattern. Some road side trees often block the vision of the drivers and helpers to maintain the vehicle properly.

The Roads and Highways Department (RHD) has high duty to impose safety indicators in many highways and urban roads. A list of over 200 accident prone points was made by the Accident Research Institute (ARI) but unfortunately RHD failed to take any milestone approach regarding such black spots of the road. The manpower of Road design and safety circle of RHD is very weak to work out in the identified black spots.

\subsection{Carelessness of the Traffic Police}

The corruption and carelessness of the traffic police is another battering for causing road accidents in Bangladesh. Drivers without license often do not face punishment due to huge corruption of police at the traffic management. Giving bribe to traffic police by both owners and drivers are common issue of Bangladesh. Illegal parking and reckless driving are often unseen by traffic police. Overloaded trucks pay high amount of bribe to the concerned traffic police and get acquittal from the grip of law. Traffic polices never give high restrictions to follow traffic rules like putting on seat belts, driving in proper line and speed control (Sharmeen 2011).

\section{Recommendations}

For enhancing road safety situations in Bangladesh some safety measures are prescribed below:

i. To conduct necessary and immediate survey in all over the country on the condition of national highways and adopt suitable measure to repair. More sincere function is necessary from the local authority and vehicle body inspector to block unworthy vehicles on road which are the major contributor of the road accidents.

ii. To ensure signs, road marking and effective signal system for pedestrian safety together with pedestrian segregation, improved footpath facilities, improved road crossing facilities, speed controlling devices must be ensured by adequate and proper engineering mechanism.

iii. To fix the speed limit on basis of design and pattern of the roads as speed is one of the major contributing factors of road crashes. So speed breakers and cautionary signs should be developed and ensured at location where concentration of pedestrians is necessary.

iv. True and effective maintenance of both public and private vehicle should be ensured and inspired by the government. Having and maintaining good materials for vehicles should be monitored by strict government rules to confirm desired standard of vehicle.

v. To construct both national highways and intra district road in a sustainable ways as this is beneficial for vehicles and road safety. Every vehicle of 10 years and more should be banned from driving on roads. There shall be strong process of fitness certification method that shall cover suspension and tie-rod checks.

vi. Stations and check posts should be formed on all national highways to control over loading of trucks and pick-ups. Along with this locally made vehicles should be re-examined for the purpose of safety. Better 
equipments must be provided to the highway police department and they must not act as a means of harassment and extortion.

vii. Process of providing driving license must be computerized and free of corruption. Proper education and training system must be introduced to train up the drivers about ins and outs of all vehicles maintenance.

viii. Time to time updating of list of black spots for accidents must be performed and priority action plan must be adopted properly. There can be a National Traffic Training Academy to review the current approach to traffic management.

ix. To evict all the pity shops, huts and tea-stalls from road side which are established unlawfully. Many of the areas and footpaths near road which are under the illegal possession must be recovered.

$\mathrm{x}$. Time to time health testing system must be made compulsory for the drivers to refrain them from addition to drug. Before granting and renewing of license drivers must go through some pathological test to assure that they do not take narcotic substances.

xi. Last but not the least, law must be precise and updated as well as law enforcing agency must be performing their duty without corruption as they are the most responsible authority to took over the observation of traffic laws around the transport system of the country.

\section{Conclusion}

This article has made an approach to overview the overall safety deficiencies regarding road accidents in Bangladesh with specific importance on pedestrians, non-motorized vehicles and heavy vehicles crashes together with life expectancy. It is not at all expected that road accidents will be totally removed from the country. The way to control road accident is in our hand as it is not a natural disaster. Ensuring about proper remedy must be considered by the policy makers before many more lives are taken away by this threat of road accidents. Road accident is such as case which does not occur by itself but operated by the careless drivers while driving aggressively. More strict and competent legislations should be introduced to bring the situation under control. An attempt has been made by the paper to highlight the cases of road accidents of Bangladesh. Influence on the number and severity of road accidents have been made by many varied factors and issues. Driving speeds along with human issues like driver's attitude, driving skill, use of roads by pedestrians are the main contributors in the road accidents. Some environmental factors like road condition, road side activities, weather condition etc have added distress in the chapter of road accidents. Speed restriction can play significant role to reduce road crashes. The target to lower the rates of road accidents cannot be sustained without collective approach all stakeholders working in road management. Although a horrific scenario of road accident is there in Bangladesh but still the inclusion of 'road safety' as a component of all road construction made by RHD can be treated as a modern decision. The Government along with common people shall also be concern about the traffic laws to make joint commitment on road safety.

\section{References}

- Sharmeen \& Islam (2011). Road Accidents: Contemporary Scenario and Policy Issues in Bangladesh. Journal of Bangladesh Institute of Planners, Vol. 4, pp. 45-55

- $\quad$ Kopits, E. (2005). Traffic Fatalities and Economic Growth. Acid. Anal. Prev., 37 (1), pp. 169-178

- Siddiqui, M.S. (2016). Waiting for a Suitable Traffic Law. Financial Express. Dhaka

- Wijnen, W. (2013). Social Costs of Road Crashes: an International Comparison Contribution. 16 $6^{\text {th }}$ Road Safety on Four Continents Conference, China

- $\quad$ WHO. (2018). Global Status Report on Road Safety 2018. WHO Press

- Jahan, A. A. (2006). Road Safety Countermeasures and Traffic Calming Practices in Roads and Highways Department (RHD) in Bangladesh. Paper presented in International Conference on Road safety in developing countries, organized by Accident Research Centre (ARC), BUET, Dhaka, 22-24 August, 2006

- Sikdar, P.K. (2009). Transport and Communications Bulletin for Asia and the Pacific. Road safety scenario in India and proposed action plan, pp. 1-16

- Banerjee, D. Chawkraborty. (2009). Appraisal and mapping the spatial-temporal distribution of urban road traffic noise. International Journal of Environmental Science and Technology. Vol 6(2),pp 325-335

- Bangladesh Bureau of Statistics (BBS) (2001). Urban area report of Bangladesh. Vol 1. Ministry of Planning, Government of Bangladesh, Dhaka

- Centre for Urban Studies (CUS) (2006), National Institute of population research and Training (NIPORT) and MEASURE Evaluation, Slums of Urban Bangladesh: Mapping and Centre, Dhaka, Bangladesh and Chepel Hill, USA.

- UNESCAP (2007). Local Government in the Asia and the Pacific: A comparative study, country paper: Bangladesh, www.unescap.org, accessed on November 22, 2018.

- RHD Road User Cost Annual Report for 2004-2005, Department of Roads and Highway, Ministry of 
communication, Bangladesh, pp. 12-13

- Khan, S. M. (2012). Vehicle Depreciation caused by Stop-And-Go Situation in Dhaka City. International Conference on Traffic and Transport Engineering, Belgrade, Serbia, pp. 131-139

- Moniruzzaman, K. M. (2005). Road Accidents in Bangladesh. IATSS research, vol 29(2).

- Hasan, T. (2004). Human factors for safe and efficient roadway design and operation. Journal of Civil engineering. Vol 32, pp. 163-172

- Islam, S. (2012). Pedestrian safety in Bangladesh: Some Research Findings. In $1^{\text {st }}$ International Conference on Advances in Civil Engineering, CUET, Chattogram, Bangladesh.

- Mahmud, S.M.S. (2011). Road safety research in Bangladesh: constraints and requirements. $1^{\text {st }}$ Civil Engineering Congress, Dhaka, Bangladesh, pp. 162-171

- Ahsan, H.M. (2002). Traffic Safety in Dhaka City: Key Issues and Countermeasures. Journal of Civil Engineering (IEB), Vol 30, pp. 13-24

- The Daily Star, 2011. Retrieved from http://edailystar.com/index.php?opt=view\&page=22\&date=201-08-16 on 22 November, 2018 